\title{
Percepção de pessoas submetidas ao transplante renal sobre a doação de órgãos
}

\section{Perception of people undergoing kidney transplantation about organ donation} \author{
Paulo Roberto Boeira Fuculo Junior ${ }^{2,5}$, Eda Schwartz ${ }^{1,2}$ \\ ${ }^{1}$ Programa de Pós-Graduação em Enfermagem, Universidade Federal de Pelotas (UFPel) - Pelotas (RS), Brasil. \\ ${ }^{2}$ Núcleo de Condições Crônicas e suas Interfaces (NUCCRIN) - Pelotas (RS), Brasil. \\ ${ }^{3}$ Universidade Federal de Juiz de Fora (UFJF) - Juiz de Fora (MG), Brasil. \\ ${ }^{4}$ Departamento de Enfermagem Pediátrica, UFPel - Pelotas (RS), Brasil. \\ ${ }^{5}$ Curso de Enfermagem, Faculdade de Enfermagem UFPel - Pelotas (RS), Brasil.
}

Bianca Pozza dos Santos ${ }^{1,2}$, Aline da Costa Viegas ${ }^{1,2}$, Elaine Amaral de Paula1,3, Fernanda Lise ${ }^{1,2,4}$, Luiza Pereira Vargas Rodrigues ${ }^{2,5}$

DOI: https://dx.doi.org/10.7322/abcshs.v43i1.928

\section{RESUMO}

Introdução: A doença renal crônica apresenta elevada prevalência e morbimortalidade no Brasil e no mundo, sendo responsável por perdas sociais, econômicos e na qualidade de vida. Dentre as modalidades de terapia renal substitutiva, o transplante é considerado o melhor tratamento, pois apresenta menor custo, propicia maior qualidade de vida e aumento da sobrevida. Todavia, a realização de um transplante somente é possível a partir da doação de um órgão. Objetivo: Conhecer as percepções das pessoas submetidas ao transplante renal sobre a doação de órgãos. Métodos: Estudo descritivo e qualitativo, em que 20 pessoas com o transplante renal participaram. A análise dos dados seguiu as fases: ordenação, classificação dos dados e análise final. Resultados: Os dados apresentam a manifestação sobre a necessidade da doação de órgãos, sendo estimulada a promoção pelos meios de comunicação, ainda que somente a família possa optar pela doação quando se depara com a morte de um ente querido, a questão da compatibilidade do órgão para o receptor, o esforço para poder realizar a doação e o recomeçar a vida. Conclusão: Para os participantes, a doação de órgãos, especialmente a do rim, consiste em um evento positivo na vida da pessoa que recebe o enxerto renal. Com a realização do sonho de ser transplantado, há um renascimento para continuar a vida.

Palavras-chave: insuficiência renal crônica; transplante de rim; obtenção de tecidos e órgãos.

\begin{abstract}
Introduction: Chronic kidney disease has high prevalence and morbidity/mortality in the Brazil and in the world, being responsible for social, economic and quality of life losses. Among the modalities of renal substitutive therapy, the transplantation is considered the best treatment because it presents lower cost, provides higher quality of life and increased survival. However, the realization of a transplant is possible only from the donation of an organ. Objective: To know the perceptions of people undergoing kidney transplantation about the organ donation. Methods: Descriptive and qualitative study, in which 20 people with renal transplantation participated. The analysis of the data followed the phases: ordering, classification of data and final analysis. Results: The data present the manifestation about the need of organ donation, being encouraged by media promotion, although only the family can take the option for donation when it comes with the death of a loved one, the question of the compatibility of the organ for the recipient, the effort to be able to realize the donation and to recommence the life. Conclusion: For the participants the donation of organs, especially the kidney, consists of a positive event in the life of the person which receives the renal graft. And with the realization of the dream of being transplanted, there is a rebirth to continue life.
\end{abstract}

Keywords: renal insufficiency, chronic; kidney transplantation; tissue and organ procurement.

Recebido em: 23/02/2017

Revisado em: 05/09/2017

Aprovado em: 15/12/2017

Autora para correspondência: Bianca Pozza dos Santos - Universidade Federal de Pelotas - Rua Gomes Carneiro, 1 - Centro - CEP: $96010-610$ - Pelotas (RS), Brasil -E-mail: bi.santos@bol.com.br

Apoio financeiro: LPVR recebeu bolsa PROBIC/FAPERGS, PRBFJ recebeu bolsa do Programa de Educação Tutorial (PET) e ES recebeu Bolsa de Produtividade CNPq.

Conflito de interesses: nada a declarar. 


\section{INTRODUÇÃO}

A doença renal crônica (DRC) ocorre quando existem modificações estruturais nos rins ou nas suas funções, por um período superior a três meses, podendo ou não influenciar na filtração glomerular, levando a alterações no estado de saúde da pessoa ${ }^{1}$. As principais causas conhecidas de lesão renal são a diabetes mellitus e a hipertensão arterial sistêmica. Desse modo, a DRC apresenta elevada prevalência e morbimortalidade no Brasil e no mundo, sendo responsável por prejuízos sociais, econômicos e perda na qualidade de vida ${ }^{2}$.

O diagnóstico precoce e o tratamento adequado da doença são estratégias que permitem a preservação da função renal ao longo do tempo, reduzindo os danos inerentes a essa condição. As diretrizes da Kidney Disease: Improving Global Outcome (KDIGO) para DRC recomendam que todas as pessoas que procuram um serviço de saúde devem ser avaliadas para verificar os riscos de desenvolvimento de doença renal ${ }^{1}$. Ainda, essas diretrizes possibilitam a detecção da DRC em fases iniciais, quando é assintomática, e isso contribui na diminuição da sobrecarga de morbidade e de mortalidade, principalmente, sendo relacionada à doença cardiovascular ${ }^{3}$.

O tratamento conservador da DRC pode diminuir a progressão da doença e postergar o início da terapia renal substitutiva (TRS), aumentando a qualidade de vida por meio da preservação das condições clínicas, psicológicas e sociais. Contudo, observa-se que o diagnóstico da DRC é realizado no momento em que a pessoa já desenvolveu a falência funcional renal (FFR) e encontra-se na fase mais avançada da doença, apresentando sintomatologia urêmica, necessitando iniciar a TRS, como a hemodiálise, a diálise peritoneal ou o transplante renal. Dentre essas modalidades de TRS, o transplante renal é considerado o melhor tratamento, uma vez que apresenta menor custo, propicia maior qualidade de vida e aumento da sobrevida, sendo indicado em casos de FFR em fase dialítica ou pré-dialítica e podendo ser realizado com doador vivo ou falecido ${ }^{4}$.

O Brasil é destaque mundial na coordenação e na regulamentação de transplantes de órgãos em serviços públicos. Desde 1997, o Sistema Nacional de Transplantes (SNT) foi responsável pelo incremento de 3.710 casos de transplantes renais no período de 1988 a 2010. O Ministério da Saúde (MS) disponibiliza custeio para despesas relacionadas à captação de órgãos, cirurgias, tratamento de complicações, atendimento ambulatorial e fornecimento de medicamentos imunossupressores ${ }^{5}$. Com a disponibilização de novos medicamentos e o aprimoramento das técnicas cirúrgicas, a sobrevida das pessoas com o transplante renal tem sido cada vez maior. Atualmente, o tempo médio aproximado de sobrevida, após o quinto ano de transplante, é de $70 \%$ para o enxerto e de $80 \%$ para o receptor ${ }^{6}$.

A realização de um transplante somente é possível a partir da doação de um órgão. O processo de doação é permeado por um conjunto de ações e de procedimentos que tem a finalidade de identificar o potencial doador e de torná-lo um doador efetivo.
Estudo aponta que um dos principais problemas na efetivação da doação de órgãos é a falta de informação por parte dos profissionais. Além disso, crenças religiosas, desconhecimento e medo são aspectos relacionados à recusa na doação de órgãos ${ }^{7}$.

Nesse sentido, as campanhas midiáticas têm contribuído para fomentar a discussão deste tema. Estudo realizado no Brasil com o objetivo de identificar as mudanças na qualidade de vida após a efetivação do transplante renal verificou que o procedimento teve impacto positivo na melhora da qualidade de vida de pessoas com a DRC, independente de fatores sócio-demográficos ${ }^{8}$. Então, ao considerar as experiências de pessoas transplantadas renais no processo de doação de órgãos e o impacto no estilo de vida delas, o presente estudo teve como objetivo conhecer as percepções das pessoas submetidas ao transplante renal sobre a doação de órgãos.

\section{MÉTODOS}

Recorte de um estudo descritivo de abordagem qualitativa, realizado em três serviços de TRS localizados em um município da região Sul do Brasil. Os critérios de inclusão para a seleção dos participantes foram: idade igual ou superior a 18 anos; disposição em participar do estudo; concordância com a gravação da entrevista; aceitar a divulgação dos dados nos meios científicos; ter preservação da comunicação verbal e cognição; estar vinculado ao serviço de nefrologia; ter realizado há, no mínimo, um ano do transplante renal; ter realizado alguma TRS anterior (hemodiálise ou diálise peritoneal). Já os critérios de exclusão foram relacionados àquelas pessoas que realizaram o transplante renal, mas retornaram ao tratamento dialítico.

O contato com os participantes ocorreu por telefone, mediante uma lista com a relação de pessoas que haviam realizado o transplante renal, cedida pelos três serviços de TRS. Após o aceite em participar do estudo, havendo a apresentação dos objetivos propostos, foram agendados o horário e o local das entrevistas.

Dos 85 nomes presentes na lista fornecida pelos três serviços de TRS, alguns não se encaixavam nos critérios de inclusão e outros recusaram o convite para a participação no estudo. Assim, conseguiram-se contatar para participar 20 pessoas com o transplante renal de ambos os sexos para o conhecimento da vivência com o transplante renal. Ao todo, participaram dez homens e dez mulheres, na faixa etária de 30 a 63 anos de idade.

A coleta de dados, realizada no domicílio e nos serviços de nefrologia no período de maio a julho de 2013, foi por meio de entrevistas com dois roteiros. O primeiro com perguntas para identificar o perfil sociodemográfico, o tempo do transplante renal na vigência da entrevista, o local de realização e a fonte do órgão transplantado. O segundo possuía perguntas semiestruturadas para conhecer as vivências das pessoas com o transplante renal: Conte-me sobre como foi a sua vida após a realização do transplante renal? Com o transplante renal, o que você considerou fácil? Com o transplante renal, o que você considerou difícil? 
As respostas foram gravadas em áudio, com uma duração total de 607 minutos. Após, os dados deste recorte foram analisados de acordo com a proposta operativa da autora Minayo, seguindo as etapas: ordenação, classificação dos dados e análise final ${ }^{9}$.

Referente aos procedimentos éticos, o Termo de Consentimento Livre e Esclarecido (TCLE) foi apresentado para os participantes antes de iniciar a entrevista. Assim, foi explicada a finalidade do estudo, o livre acesso aos dados, a liberdade de desistir em qualquer momento e a garantia do anonimato, sendo identificados pela letra $\mathrm{E}$, de entrevistado, pelo número arábico, conforme a sequência das entrevistas, pelo sexo e pela idade.

Respeitou-se ainda a Resolução 196/96 do Conselho Nacional de Saúde do Ministério da Saúde, que estava em vigor, na qual estabelecia as regras para a realização de pesquisas que envolvem pessoas. O estudo recebeu aprovação do Comitê de Ética em Pesquisa, sob n 192/2013.

\section{RESULTADOS}

Diante dos resultados encontrados no estudo, destaca-se a manifestação de um relato sobre a necessidade da doação de órgãos. O participante E16 afirmou sobre o trabalho do meio de comunicação e sua importância para a promoção dos transplantes. Ainda relatou que, na década de 1990, quando iniciou de maneira mais efetiva a campanha de doação, a permissão do doador se dava através de um registro de autorização no documento de identificação.

Quando eu entrei na hemodiálise em 1998, a [nome de uma emissora regional] até me entrevistou na época. [...] Eles falavam muito naquela época que não tinha doação. Claro, hoje ainda é difícil, mas naquela época era muito pior e eu dizia que tinha que ter uma coisa que o governo e as pessoas tinham que se conscientizar desde as escolas, desde criança assim, de conscientizar disso aí [doação de órgãos], que não era um bicho de sete cabeças. E eu, graças a Deus, bem na época eu já era doador. Na minha época, tinha que botar na carteira de identidade. Era moleque, mas tinha que botar na carteira de identidade se era doador ou não era e eu sempre achei que tinha que ser doador (E16, 40 anos, masculino).

Quando eu vejo esse tipo de campanha [campanha de doação de órgãos], geralmente no Facebook, na televisão, ou qualquer outro lugar, eu sempre fico torcendo para que as pessoas vejam aquilo ali e que se conscientizem a doar, a ajudar as outras pessoas, porque são coisas que [...], como é o caso do doador cadáver, a pessoa já está com morte cerebral, não tem mais o que fazer. Se a família não resolver doar, os órgãos vão morrer junto com a pessoa. Se a família resolver tomar essa atitude de fazer a doação, pode melhorar a vida de várias pessoas. [...] Se eu fosse depender de alguém querer me doar, não sei se eu não estaria esperando até agora. Porque às vezes, não se trata nem de boa vontade, às vezes se trata da pessoa ter a característica certa, ser compatível, não ter problema de saúde (E5, 30 anos, masculino).

Com a importância de haver campanhas midiáticas para a promoção da doação de órgão, o participante E5 ressalva o desejo de que mais pessoas sejam beneficiadas pelo transplante. Ainda salienta que somente a família poderá optar pela doação quando se depara com a morte de um ente querido e a questão da compatibilidade do órgão, na qual o participante E7 também abordou, pois muitas vezes, há o desejo dos familiares serem doares vivos, mas são confrontados com a não compatibilidade do órgão para o receptor.

Só quem precisou e sabe o que é. Tu estás numa expectativa que tu não sabes se vai receber ou se não vai receber, é complicado. Talvez tu vê mãe, pai quererem doar e não é compatível. Eu conheço uma menina [...] que a mãe queria doar e não era compatível com ela. Então é complicado (E7, 58 anos, feminino).

Já o participante E11 comenta sobre a dificuldade que teve de aceitar que seu familiar doasse o rim, mas acabou aceitando em virtude de achar que não teria muito tempo de vida se somente dependesse da hemodiálise, como tratamento para a DRC. Enquanto E15 fala do esforço realizado por sua irmã para poder realizar a doação.

Os médicos me garantiram que não era hereditário [doença renal crônica], que era um problema meu, que não era uma coisa que eu me preocupasse, que não era problema de família, mas pela insistência dos meus irmãos, eu acabei aceitando [a doação], porque eu passava mal na hemodiálise. Então, eu tinha certeza que não iria durar muito por causa da hemodiálise e acabei aceitando a doação do irmão (E11, 54 anos, masculino).

A coisa mais difícil é conseguir um rim. [...] Hoje em dia, [...] tu tens problema renal, ainda tu tens aquele modo de viver que é aquelas máquinas [hemodiálise]. Tu tens uma opção [...] e ela [irmã] teve que emagrecer 27 quilos em um ano, para poder me doar o rim. Então, aí que eu tenho que dar mais valor (E15, 39 anos, masculino).

Com a questão da doação de órgãos e dos benefícios muitas vezes proporcionados para a vida da pessoa com a DRC, o participante E5 ainda faz um relato sobre a necessidade de haver maior divulgação sobre o assunto.

Eu acho que se tivesse alguma coisa para dizer, seria no sentido de procurar formas que conscientizassem mais as pessoas, principalmente, os profissionais que vão trabalhar na área da saúde [...], porque eu não sei como é que está essa situação hoje aqui no Estado, se é bem divulgado isso (E5, 30 anos, masculino). 
Outro dado encontrado foi o fato dos participantes fornecerem conselhos para as pessoas com a DRC que estão em tratamento dialítico, a entrarem na fila de espera para a obtenção do órgão para o transplante, como abordou E10. E, como afirmou E20, os participantes consideram o rim recebido como o começo de uma nova vida.

É a melhor coisa que tem, que eu indico assim, é entrar na fila, se não tem um doador, é entrar na fila para poder fazer o transplante (E10, 46 anos, feminino).

Então eu acho que o rim é uma vida nova. Tu praticamente podes considerar como que tu tenhas renascido, nascido de novo (E20, 63 anos, feminino).

Esses depoimentos apresentados revelam que, muitas vezes, ser beneficiado com o transplante renal significa o renascimento de uma vida marcada pelo sofrimento da DRC e do tratamento dialítico imposto. Nesse contexto, o começo de uma nova existência passa a ser sentida com maior intensidade.

\section{DISCUSSÃO}

O transplante renal é uma prática rotineira em cerca de 80 países do mundo, sendo realizado em maior número nos Estados Unidos, na China, no Brasil e na Índia. Já as populações que se beneficiam melhor com o seu acesso são da Áustria, dos Estados Unidos, da Croácia, da Noruega, de Portugal e da Espanha ${ }^{4}$.

O Brasil é considerado o país com o maior número de transplante renal com financiamento do sistema público, realizando cerca de 20 mil procedimentos por ano e possuindo uma das maiores filas do mundo, que é em torno de 20 mil pessoas, em um número estimado de 91 mil pacientes em tratamento de hemodiálise $^{10}$. Apesar disso, poucos estudos abordam como ocorre o acesso ao transplante de rim e suas repercussões ${ }^{11}$.

Assim sendo, são preocupantes a crescente desproporção entre a alta demanda por transplantes de órgãos e o baixo índice de transplantes efetivados. Com isso, faz-se necessário reduzir os erros ao identificar o possível agente para a doação de órgãos e as não indicações estabelecidas pelos profissionais assistentes, seguindo as diretrizes para a avaliação e a validação do potencial doador de órgãos em morte encefálica ${ }^{12}$.

A principal característica das listas de espera é que elas não funcionam por ordem de chegada, em que o primeiro a se inscrever receberá o órgão antes do segundo e, assim, consecutivamente. Em vez disso, os critérios obedecem às condições médicas, sendo os seguintes fatores determinantes: compatibilidade dos grupos sanguíneos e gravidade da doença ${ }^{10}$.

A literatura aponta que fatores socioeconômicos, culturais e clínicos influenciam no acesso e na decisão de realizar o transplante renal. Dentre eles, destaca-se o menor tempo de espera para a realização em pessoas que apresentaram alguma das seguintes condições: tipo sanguíneo A; exerciam atividades profissionais; menor tempo em diálise e inscrição na lista de espera ${ }^{11}$.

Além disso, há muitas limitações referentes ao acesso ao transplante pelo mundo $\mathrm{o}^{4}$ a elevada taxa de recusa familiar (44\%) persiste como o principal obstáculo para a efetivação da doação, na maioria dos estados brasileiros ${ }^{13}$. Assim, a promoção da doação de órgãos tem ocorrido no Brasil por meio de campanhas midiáticas e de incentivos das instituições responsáveis pela saúde. Inúmeras campanhas de doação de órgãos contribuem para que ainda seja o país com a maior taxa de aceitação familiar para a doação na America Latina. Em 2014, o percentual de aceite subiu para 58\%, em que 95\% foram realizados pelo Sistema Único de Saúde (SUS) ${ }^{14}$. O objetivo das campanhas é estimular que as pessoas se tornem doadoras, para que o Brasil atinja sua meta anual de 14,4 mil doadores por milhão ${ }^{15}$.

Conforme os resultados deste estudo, os depoimentos trazem manifestações sobre a necessidade de existirem mais doações. O participante E5 manifesta seu desejo e incentivo à doação de órgãos quando vê as campanhas na mídia, assim como, enxerga a doação de pessoas falecidas como uma forma de ajudar outras pessoas, não "perdendo" os órgãos de quem morreu, mostrando o papel fundamental da família para que esse processo ocorra.

Embora o percentual de doações tenha aumentado ainda muitas famílias rejeitam a doação de órgãos de seu ente querido em morte encefálica. Isso ocorre porque no Brasil somente o familiar pode autorizar a doação ${ }^{15}$, ao contrário do que ocorria antigamente, em que a autorização para a doação era indexada na carteira de identidade, como afirmado por E16. Considera-se que a dificuldade de entender a morte e a dor do luto são fatores que inviabilizam a autorização, uma vez que o contexto cultural, as concepções religiosas e as fantasias criadas em cima do tema de doação constituem substrato para a representação em torno de todo o processo de transplante ${ }^{16}$.

Em contrapartida, com relação ao doador vivo, esse pode ser algum membro da família ou amigo. Além de passar por uma avaliação clínica, o mesmo deverá ser compatível sanguineamente, manifestar sua vontade de doar, ser maior de 18 anos e estar em boas condições de saúde ${ }^{17}$, havendo ainda, a ordem judicial. Quanto à compatibilidade relatada por alguns dos participantes deste estudo, o receptor só receberá o rim se os testes de histocompatibilidade (HLA) e de cross-match forem positivos, eliminando as chances de transmissões de doenças no processo de transplante ${ }^{18}$.

Nesse contexto, destaca-se um estudo realizado com famílias que passaram pelo processo de doação de órgãos, mais precisamente o rim, em que foi evidenciado que uma das fases desse processo é o medo da incompatibilidade, ou seja, do corpo não aceitar o enxerto e do fracasso da cirurgia. Todavia, o transplante resultou no amadurecimento da família e no estreitamento dos vínculos, principalmente quando se fala da escolha do doador familiar de uma forma espontânea frente à falta de possibilidades ${ }^{19}$. Fato esse que corrobora com a percepção dos participantes deste estudo, como E7 que expressou o seu sentimento na época em que 
aguardava na lista de espera, de ficar na expectativa de receber ou não o rim, afirmando que muitas vezes, o desejo do familiar próximo querer doar, mas não ser compatível.

O preparo para o transplante renal entre vivos em que envolve doador é gerador de tensão e de ambivalência de sentimentos nos envolvidos, principalmente, a pessoa e o provável doador que, na maioria das vezes, é um membro da família ${ }^{19}$. Assim, o preparo para o transplante entre vivos precisa seguir um protocolo que inclua a garantia de segurança ao doador e determinar se ele é capaz de oferecer o enxerto adequado para o transplante ${ }^{20}$. A expectativa de que o familiar possa ser o doador, nem sempre é possível de se concretizar.

A doação de órgão entre vivos é motivada por valores altruístas e comerciais, os quais favorecem o aumento do número de doações de órgão entre vivos. Contudo, essa forma de doação esconde o enfretamento de familiares que se veem obrigados a compartilhar seus órgãos, despertando nos receptores, a preferência pelo rim de um doador desconhecido, evitando o sentimento de culpa por precisar aceitar o recebimento do rim de um familiar que pode ter tomado esta decisão por pressões culturais ${ }^{21}$.

Todavia, às vezes é comum que o ato da doação de um doador familiar amenize a angústia de receber um órgão desconhecido. Tal ansiedade vivenciada pela pessoa que aguarda o órgão para o transplante pode ser reduzida com o acolhimento da equipe de enfermagem, promovendo a escuta, valorizando as práticas de cuidado e gerando sentimentos de segurança nos envolvidos (receptor e doador) ${ }^{19}$.

O profissional da saúde, sobretudo, o enfermeiro, pode atuar como educador para que consiga modificar a opinião pública sobre a doação de órgãos, fazendo com que as pessoas possam debater e opinar no processo de doação, uma vez que para modificar a realidade existente são necessários programas planejados e avaliados, aos quais devem ser destinados aos vários seguimentos da sociedade ${ }^{7}$. Para isso, promover educação continuada e capacitação das equipes de saúde a nível hospitalar e de atenção básica são atitudes indispensáveis para qualificar os profissionais e tornar a discussão sobre doação de órgãos uma pauta familiar, quebrando as barreiras entre o hospital e a atenção básica ${ }^{22}$.

Para corroborar com essa afirmativa, estudo realizado demonstrou que a falha de identificação e de notificação tardia de potenciais doadores, bem como a falta de infraestrutura e a recusa familiar, representam grande parte do insucesso no processo de doação de órgãos. Ainda, a falta de conhecimento dos profissionais de enfermagem pode influenciar na escolha da família.
Entretanto, as competências clínicas necessárias para atuar em todo o processo de transplante vão além de todas aquelas adquiridas na graduação de enfermagem ${ }^{23}$. Essa ideia reforça a necessidade de capacitar os profissionais de enfermagem para atuarem de forma integral no processo de transplantação.

Para os participantes deste estudo, a doação de órgãos, especialmente a do rim, consiste em um evento positivo na vida da pessoa que recebe o enxerto. Na percepção deles com a concretização do sonho de ser transplantado, há um renascimento para poderem dar continuidade à vida. Nessa perspectiva, almejam que as pessoas sejam estimuladas a doarem os órgãos do ente que faleceu, inclusive, a partir da justificativa de que parte do corpo do familiar poderá permanecer "viva", com o intuito de promover as doações.

Eles compreendem que receber o rim transplantado envolve muitas circunstâncias, os quais poderiam dificultar a doação como os aspectos relacionados à compatibilidade e a necessidade de o doador não ter problemas de saúde. Diante disso, muitos vivenciaram períodos de tempos e diferentes expectativas na lista de espera. Apesar de todos os anseios promovidos pela espera, ainda incentivam que as pessoas com a DRC em tratamento hemodialítico entrem para a fila, pois, o viver pós-transplante é recompensador.

Quando a compatibilidade surge, outros dilemas são identificados como, por exemplo, aceitar o órgão de um familiar em decorrência dos sacrifícios que o doador tem que perpassar em detrimento do transplante. Desse modo, sentem-se obrigados a retribuir e valorizar a pessoa pelo ato de doar.

Diante dessa contextualização, os participantes sugerem que seja ampliada a divulgação a respeito da doação de órgãos nos meios midiáticos, com vistas à conscientização das pessoas para a realização e para o aumento nos índices dos transplantes, sobretudo, o renal. Sendo assim, infere-se que profissionais da saúde e a população em geral necessitam colaborar para a promoção e para a conscientização dos transplantes no Brasil.

A limitação do estudo diz respeito ao objetivo da pesquisa que derivou estes dados, uma vez que não era sobre a percepção das pessoas no que tange aos transplantes, mas foi um assunto abordado e valorizado com frequência pelos participantes. Percebeu-se que não houve um aprofundamento sobre o tema, sendo identificada a necessidade de se investir em pesquisas nesta área. Destaca-se que apresentar a percepção das pessoas transplantadas renais sobre o tema é de grande relevância para justificar a importância da doação de órgãos em prol da vida das pessoas que necessitam.

\section{REFERÊNCIAS}

1. Kindney Diseases Improving Global Outcomes (KDIGO). KDIGO 2012 Clinical practice guideline for the evaluation and management of chronic kidney disease. Chapter 1: definition and classification of CKD. Kidney Int Suppl. 2013;3(1):19-62.

2. Sesso RC, Lopes AA, Thomé FS, Lugon JR, Martins CT. Inquérito brasileiro de diálise crônica 2014. J Bras Nefrol. 2016;38(1):54-61. http://dx.doi.org/10.5935/0101-2800.20160009
3. Middleton JP, Pun PH. Hypertension, chronic kidney disease, and the development of cardiovascular risk: a joint primacy. Kidney Int. 2010;77(9):753-5.

http://dx.doi.org/10.1038/ki.2010.19

4. Garcia GG, Harden P, Chapman J. O papel global do transplante renal. J Bras Nefrol. 2012;34(1):1-7.

http://dx.doi.org/10.1590/S0101-28002012000100001 
5. Medina-Pestana JO, Galante NZ, Tedesco-Silva Jr H, Harada KM, Garcia VD, Abbud-Filho M, et al. O contexto do transplante renal no Brasil e sua disparidade geográfica. J Bras Nefrol. 2011;33(4):472-84

http://dx.doi.org/10.1590/S0101-28002011000400014

6. Brasil. Ministério da Saúde. Coordenação geral do sistema nacional de transplantes [Internet]. Rim. Disponivel em: http:// portalsaude.saude.gov.br/index.php/o-ministerio/principal/ secretarias/366-sas-raiz/dahu-raiz/transplantes-raiz/transplantes/ 21641-rim. Acesso em: 29 nov. 2016.

7. Mendonça AEO, Torres GV, Salvetti MG, Alchieri JC, Costa IKF. Mudanças na qualidade de vida após transplante renal e fatores relacionados. Acta Paul Enferm. 2014;27(3):287-92. http://dx.doi.org/10.1590/1982-0194201400048

8. Morais TR, Morais MR. Doação de órgãos: é preciso educar para avançar. Saude Debate. 2012;36(95):633-9. http://dx.doi.org/10.1590/S0103-11042012000400015

9. Minayo MCS. O desafio do conhecimento: pesquisa qualitativa em saúde. 12ed. São Paulo: Hucitec; 2012.

10. Portal Brasil. Ministério da Saúde. Saiba quais são os critérios da lista de espera por transplantes [Internet]. Doação de órgãos. Disponível em: http://www.brasil.gov.br/saude/2016/09/saiba-quais-sao-os-criterios-dalista-de-espera-por-transplantes. Acesso em: 10 nov. 2016.

11. Machado EL, Gomes IC, Assis Acurcio F, César CC, Mattos Almeida MC, Cherchiglia ML. Fatores associados ao tempo de espera e ao acesso ao transplante renal em Belo Horizonte, Minas Gerais, Brasil. Cad Saúde Pública. 2012;28(12):2315-26. http://dx.doi.org/10.1590/S0102-311X2012001400010

12. Westphal GA, Garcia VD, Souza RLD, Franke CA, Vieira KD, Birckholz VRZ, et al. Diretrizes para avaliação e validação do potencial doador de órgãos em morte encefálica. Rev Bras Ter Intensiva. 2016;28(3):220-55.

http://dx.doi.org/10.5935/0103-507X.20160049

13. Associação Brasileira de Transplantes de Órgãos (ABTO). Transplantes de rim. Registro Bras Transplantes. 2015;22(2):6.

14. Portal Brasil. Ministério da Saúde [Internet]. Campanha sobre doação de órgãos destaca história de atletas transplantados.
Disponível em: http://www.brasil.gov.br/saude/2015/10/campanhade-doacao-de-orgaos-traz-historias-de-atletas-transplantados. Acesso em: 9 ago. 2016.

15. Aliança Brasileira pela Doação de Órgãos e Tecidos (ADOTE) [Internet]. Notícias. Governo Federal lança campanha para a doação de órgãos. Disponível em: http://www.adote.org.br/ noticias/governo-federal-lanca-campanha-para-doacao-deorgaos. Acesso em: 30 nov. 2016.

16. Kurtz CTL, Weber BT, Quintana AM, Castro EK. Doação de órgãos: um estudo em representações sociais na saúde. Dissertação (Mestrado) Universidade Federal de Santa Maria. Santa Maria: 2012.

17. Portal Brasil. Ministério da Saúde [Internet]. Informe-se sobre o processo de doação de órgãos e tecidos. Disponível em: http:// www.brasil.gov.br/saude/2009/11/informe-se-sobre-o-processode-doacao-de-orgaos-e-tecidos. Acesso em: 02 dez. 2016.

18. Sociedade Brasileira de Nefrologia. Tratamentos - transplante renal [Internet]. Disponível em: http://sbn.org.br/publico/ tratatamentos/transplante-renal. Acesso em: 02 dez. 2016.

19. Cruz MGS, Daspett C, Roza BA, Ohara CVS, Horta ALM. Vivência da família no processo de transplante de rim de doador vivo. Acta Paul Enferm. 2015;28(3):275-80. http://dx.doi.org/10.1590/1982-0194201500046

20. Silveira F. Rotinas em transplante de fígado, pâncreas e rim. Instituto para Cuidado do Fígado; 2015.

21. Scheper-Hughes N. A tirania e o terror da dádiva: a violência sacrificial e o dom da vida. Cad Estudos Sociais Politicos. 2014;3(5):1-22.

22. Rodrigues TMM, Moura LKM, Gomes RMC, Sousa MCP, Sousa PCC, Lago EC. Doação de órgãos: percepção das famílias com pacientes internados em hospitais gerais. Rev Interdisciplinar. 2014;7(1):152-61.

23. Souza ATS, Freire VS, Silva AJS, Medeiros MCA, Vasconcelos FM, Ponte MAV. A atuação do enfermeiro no processo de doação de órgãos: uma revisão integrativa. Rev Interdisciplinar. 2014;7(3):138-48. 